\title{
Do females behave differently in COPD exacerbation?
}

This article was published in the following Dove Press journal:

International Journal of COPD

24 April 2015

Number of times this article has been viewed

Hatice Kilic'

Nurdan Kokturk ${ }^{2}$

Gulcin Sari ${ }^{3}$

Mustafa Cakır ${ }^{4}$

'Department of Pulmonary Medicine, Ankara Atatürk Training and Research Hospital, ${ }^{2}$ Department of Pulmonary Medicine, School of Medicine, Gazi University School of Medicine, ${ }^{3}$ Department of Pulmonary Medicine, Dr. Nafiz Körez Sincan Devlet Hastanesi, ${ }^{4}$ Department of Public Health, School of Medicine, Gazi University, Ankara, Turkey
Correspondence: Nurdan Kokturk Department of Pulmonary Medicine, School of Medicine, Gazi University School of Medicine, 06500 Besevler, Ankara, Turkey

Tel +903122026121

$\mathrm{Fax}+903122129019$

Email kokturk.nurdan@gmail.com
Introduction: Little is known about whether there is any sex effect on chronic obstructive lung disease (COPD) exacerbations. This study is intended to describe the possible sex-associated differences in exacerbation profile in COPD patients.

Methods: A total of 384 COPD patients who were hospitalized due to exacerbation were evaluated retrospectively for their demographics and previous and current exacerbation characteristics.

Results: The study was conducted on $109(28 \%)$ female patients and 275 (72\%) male patients. The mean age was $68.30 \pm 10.46$ years. Although females had better forced expiratory volume in 1 second and near-normal forced vital capacity, they had much impaired arterial blood gas levels (partial oxygen pressure $\left[\mathrm{PO}_{2}\right]$ was $36.28 \mathrm{mmHg}$ vs $57.93 \mathrm{mmHg}$; partial carbon dioxide pressure $\left[\mathrm{PCO}_{2}\right]$ was $45.97 \mathrm{mmHg}$ vs $42.49 \mathrm{mmHg} ; P=0.001$ ), indicating severe exacerbation with respiratory failure. More females had two exacerbations and two hospitalizations, while more men had one exacerbation and one hospitalization. Low adherence to treatment and pulmonary embolism were more frequent in females. Females had longer time from the onset of symptoms till the admission and longer hospitalization duration than males. Comorbidities were less in number and different in women $(P<0.05)$. Women were undertreated and using more oral corticosteroids.

Conclusion: Current data showed that female COPD patients might be more prone to have severe exacerbations, a higher number of hospitalizations, and prolonged length of stay for hospitalization. They have a different comorbidity profile and might be undertreated for COPD.

Keywords: COPD, exacerbation, sex, female, comorbidities

\section{Introduction}

The female phenotype has gained much attention with regard to COPD due to the fact that the mortality rate of women with COPD has risen in contrast to that of men since 2000 in the United States. ${ }^{1,2}$ The rise in the mortality rate of women with COPD is principally explained by an increase in the number of women who smoke all around the world. Females might be more susceptible to the effect of smoking on lung function parameters and, therefore, may have more severe diseases. ${ }^{3}$ Several studies have shown that women have better functional parameters than men, but they have more breathlessness, worse quality of life, and less exercise capacity under stable conditions. ${ }^{4-6}$

There was a little experience about sex differences in exacerbation characteristics in COPD. ${ }^{7}$ This study is intended to describe the possible sex-associated differences in exacerbation profile in COPD.

\section{Methods}

\section{Subjects}

Six hundred eighteen patients with COPD were evaluated retrospectively from January 2000 to January 2010 at the Department of Pulmonary Medicine, Gazi University 
Hospital. In all, 384 patients (109 [28\%] female and 275 [72\%] were male) hospitalized with acute exacerbation of chronic obstructive lung disease (AECOPD) were included in the study. The patients with overlap syndrome (asthma plus COPD), overt interstitial pattern by radiology, and incomplete data were excluded from the study.

\section{Study design}

This is a retrospective cross-sectional study.

Age, body mass index, smoking status, biomass exposure, asbestos exposure, spirometric severity of airflow obstruction in stable condition, spirometry at admission, the duration of COPD, and partial oxygen pressure $\left(\mathrm{PO}_{2}\right)$ and partial carbon dioxide pressure $\left(\mathrm{PCO}_{2}\right)$ in emergency room (ER) temperature at admission were recorded and compared between the sexes.

We also determined the characterization of exacerbations in the previous year and current admission. The number of frequent exacerbators, hospital and ICU admissions, and the etiology of current exacerbations were evaluated in a comparative manner between the sexes. The study protocol was approved by the ethical committee of the institution.

\section{Definitions}

The study patients were diagnosed with COPD based on the Global Initiative for Obstructive Lung Disease guideline. ${ }^{8}$ Forced expiratory volume in 1 second/forced vital capacity $\left(\mathrm{FEV}_{1}\right) /(\mathrm{FVC})<70$ in pulmonary function test (PFT) was required to make the diagnosis of COPD. Bronchodilatation test with $400 \mathrm{mcg}$ salbutamol was routinely performed at the initial diagnosis to have a differential diagnosis of asthma. Postbronchodilator $\mathrm{FEV}_{1}$ was not systematically presented in each evaluation.

PFTs were performed with Sensormedics Vmax 20 spirometer in a sitting position while wearing a nose clip. Three full inspiration and forced expiration maneuvers were performed according to the European Respiratory Society criteria. The recorded values are taken from the best of three forced expiratory measurements. ${ }^{9}$ COPD exacerbation was defined as an increase in symptoms beyond the normal daily variability, which need a treatment change. PFT was performed to diagnose COPD grading accurately. Exacerbations that need to be treated with oral corticosteroids and/or antibiotics were defined as moderate exacerbations. Two or more moderate exacerbation per year was defined as frequent exacerbation. ${ }^{8}$

Exacerbations were defined by Anthonisen's criteria. Accordingly, the patient has to have at least one of the following three symptoms: increased dyspnea, increased sputum production, and purulent sputum..$^{10}$ Type I exacerbation (severe) is characterized by all of the three symptoms; Type II (moderate) is characterized by two of the three symptoms; Type III (mild) is characterized by only one of the three symptoms and at least one of symptoms that are related to upper airway infectious symptoms..$^{10}$ Other causes of exacerbation such as low treatment adherence and inadequate oxygen usage were also recorded, and less than 16 hours of oxygen usage is defined as inadequate usage. Low treatment adherence was determined if the patient declared that he or she frequently missed drug doses for daily purpose or if it was witnessed that he or she was unable to perform a correct inhaler technique during the admissionary evaluation. Fortunately, hospital files had information for this purpose.

The comorbidities were recorded, and Charlson scores were calculated. ${ }^{11}$ Treatment under stable condition was also recorded.

\section{Statistical analysis}

Statistical analyses were performed by using SPSS 16.0. The Shapiro Student's $t$-test was performed for the data distributed normally. Mann-Whitney $U$-test for continuous variables and chi-square test for categorical variables were used. Variables were denoted as mean \pm standard deviation, and median (minimum-maximum) statistical analyses were considered as statistically significant $(P<0.05)$.

\section{Results}

In all, 109 (28\%) female and 275 (72\%) male patients were included in the study. The mean age was $68.30 \pm 10.46$ years. A total of $40 \%$ of the admitted females and $95 \%$ of the males had a history of smoking. Current smoking rate was similar between the groups ( $23.3 \%$ vs $26.2 \%$, respectively). Passive smoking was more prevalent in females than males ( $26.7 \%$ vs $6.7 \%$, respectively). Almost $50 \%$ of the patients had biomass exposure in both groups. Asbestos exposure was slightly more prevalent in females $(20.4 \%$ vs $7.4 \%$, $P=0.2$ ) (Table 1).

Females were admitted to the hospital with a greater $\mathrm{FEV}_{1} / \mathrm{FVC}, \mathrm{FEV}_{1}, \mathrm{FVC}$, and $\mathrm{PCO}_{2}$ and lesser $\mathrm{PO}_{2}$ than males $\left(\mathrm{FEV}_{1} \%=48.9\right.$ vs $40.9 ; \mathrm{FVC} \%=136.8$ vs $54.1 ; \mathrm{PO}_{2}=36.28$ vs $57.93 ; \mathrm{PCO}_{2}=45.97$ vs 42.49 , respectively) (Table 1 ). It was interesting that air trapping implicated by reduced $\mathrm{FVC}$ seemed to be more obvious in men than women, but arterial blood gases were more impaired in women.

The characterization of the exacerbations of the previous year of the current admission is presented in Table 2. The 
Table I Characteristics of the patients

\begin{tabular}{|c|c|c|c|}
\hline & Females $(n=109)(\%)$ & Males $(n=275)(\%)$ & $P$ \\
\hline Age (mean $\pm S D$ years) & $66.69 \pm 11.19$ & $68.94 \pm 10.11$ & 0.16 \\
\hline BMI $\left(\mathrm{kg} / \mathrm{m}^{2}\right)$ & $28.26 \pm 7.08$ & $25.0 \pm 5.75$ & 0.00 \\
\hline Smoking, n (\%) & $44(40.7)$ & $261(94.9)$ & 0.00 \\
\hline Current smoker & $14(23.3)$ & $70(26.2)$ & \\
\hline Ex-smoker & $30(50)$ & $179(67)$ & \\
\hline Passive smoker & $16(26.7)$ & $18(6.7)$ & \\
\hline Biomass exposure, n (\%) & $23(46.9)$ & $21(48.8)$ & I \\
\hline Asbestos exposure, $\mathrm{n}(\%)$ & $10(20.4)$ & $2(7.4)$ & 0.2 \\
\hline Duration of COPD (years) & $6.27 \pm 6.13$ & $8.01 \pm 5.33$ & 0.00 \\
\hline Spirometric severity of COPD* & & & 0.001 \\
\hline Stage I, n (\%) & $0(0)$ & $9(3.3)$ & 0.00 \\
\hline Stage $2, \mathrm{n}(\%)$ & $27(24.8)$ & $61(22.2)$ & \\
\hline Stage $3, \mathrm{n}(\%)$ & $49(45)$ & $67(24.4)$ & \\
\hline Stage $4, \mathrm{n}(\%)$ & $33(30.2)$ & $138(50.1)$ & \\
\hline $\mathrm{FEV}_{1} / \mathrm{FVC}$ at admission & $0.645 \pm 0.14$ & $0.587 \pm 0.18$ & 0.00 \\
\hline $\mathrm{FEV}_{1}(\mathrm{~mL} / \mathrm{sn})$ at admission & $877.9 \pm 388.4$ & $I, 038.1 \pm 496.8$ & 0.00 \\
\hline $\mathrm{FEV}_{1} \%$ at admission & $48.9 \pm 15.6$ & $40.9 \pm 17.6$ & 0.00 \\
\hline $\mathrm{FVC}(\mathrm{mL})$ at admission & $\mathrm{I}, 40 \mathrm{I} .7 \pm 644.5$ & I,807.7 \pm 736.6 & 0.00 \\
\hline $\mathrm{PO}_{2}$ & $36.28 \pm 8.1$ & $57.93 \pm 12.5$ & 0.00 \\
\hline $\mathrm{PCO}_{2}$ & $45.97 \pm 7.5$ & $42.49 \pm 11.3$ & 0.00 \\
\hline
\end{tabular}

Note: *Spirometrik severity defined by GOLD.

Abbreviations: $\mathrm{BMI}$, body mass index; $\mathrm{FEV}_{1}$, forced expiratory volume in I second; FVC, forced vital capacity; GOLD, Global Initiative for Obstructive lung Disease; PO, partial oxygen pressure; $\mathrm{PCO}_{2}$, partial carbon dioxide pressure.

mean number of exacerbations that requires oral steroids or antibiotics, the mean number of ICU admissions, and the number of intubations were similar according to sex in the previous year $(P>0.05)$. The number of previously exacerbated female patients was greater than males $(92.7 \%$ vs $82.5 \%$, respectively) $(P=0.001)$. The proportion of females who had two hospitalizations was greater than men $(95.42 \%$ vs $87.27 \%)(P=0.01)$. The proportion of females who had prolonged length of hospitalization ( $>15$ days) was greater than males in the previous year $(23.9 \%$ vs $4.7 \%$, $P=0.001)$.

The characterization of the current exacerbations is presented in Table 3. Tracheobronchial infections occurred in similar frequency in exacerbations of both groups. Among the other reasons of exacerbations, low adherence to treatment and pulmonary embolism were more frequent in females. However, pneumonia was more frequent in males. Females had much longer time from the onset of symptoms till the patients were admitted to the clinic and longer hospitalization duration than males.

Women had less comorbidity than men. Women had a higher frequency of sleep disorder, chronic kidney disease, anemia, and gastroesophageal reflux disease than men. Other comorbidities were more frequent in men. Coronary artery disease, lung cancer, and other organ cancers were seen in similar proportion in both women and men (Table 4).
When the groups were compared according to treatments on stabile periods, short-acting anticholinergic agents and oral corticosteroids appeared to be taken by more women than men. However, other drugs were taken by more men than women (Table 5).

\section{Discussion}

This study showed that in a setting with hospitalized COPD patients, exposure to smoking was almost half in females when compared to males. However, current smoking rate and the biomass exposure were similar. Passive smoking and asbestos exposure, although these did not reach statistically significant levels, were seen more in females. Females had more severe exacerbations, more hospitalization due to exacerbations, and more moderate exacerbations. It may be related to BMI, which causes low-grade inflammation and associated comorbidities, such as anemia, gastroesophageal reflux, and chronic kidney disease. It may also depend on low treatment adherence in females. Lung carcinoma and coronary artery disease were seen in similar proportion in females and males. Short-acting anticholinergics usage was more common in females but oral corticosteroid was less.

COPD has been known as the lung disease of smoking men. It is more prevalent in men, and men are more affected by many COPD outcomes, including mortality. However, in 2000, for the first time, mortality rate from COPD was 
Table 2 Characteristics of exacerbations in the previous year

\begin{tabular}{|c|c|c|c|}
\hline & Females $(n=109)(\%)$ & Males $(n=275)(\%)$ & $\mathbf{P}$ \\
\hline Mean no of exacerbation \pm SD & $1.81 \pm 1.0$ & $1.78 \pm 1.27$ & 0.87 \\
\hline Number (\%) of exacerbated pts in the previous year & I0I (92.7) & $227(82.5)$ & 0.001 \\
\hline Number (\%) of pts with no exacerbations & - & - & 0.55 \\
\hline Number (\%) of pts with one exacerbation & $8(7.339)$ & $48(17.454)$ & \\
\hline Number (\%) of pts with two exacerbations & $55(50.458)$ & II 4 (4I.454) & \\
\hline Number (\%) of pts with three or more exacerbations & $46(42.203)$ & II $3(41.092)$ & \\
\hline \multicolumn{4}{|l|}{ History of receiving antibiotics due to exacerbation in the previous year } \\
\hline Mean no of antibiotic cycles \pm SD per patient & $1.42 \pm 1.30$ & $1.29 \pm 0.94$ & 0.82 \\
\hline Number $(\%)$ of pts did not receive antibiotics & $26(23.85)$ & $44(16)$ & 0.82 \\
\hline Number (\%) of pts received one or two cycles of antibiotics & $66(60.56)$ & $207(75.273)$ & \\
\hline Number (\%) of pts received three or more cycles of antibiotics & $17(15.59)$ & $24(8.727)$ & \\
\hline \multicolumn{4}{|l|}{ Hospitalization due to exacerbation in the previous year } \\
\hline Mean no of hospitalization \pm SD & $1.6 \mathrm{I} \pm 1.27$ & $\mathrm{I} .5 \mathrm{I} \pm 0.78$ & 0.34 \\
\hline Number (\%) of pts with one hospitalization & $3(2.75)$ & $32(11.63)$ & 0.01 \\
\hline Number (\%) of pts with two hospitalization & $104(95.42)$ & $240(87.27)$ & \\
\hline Number (\%) of pts with three or more hospitalization & $2(1.83)$ & $3(1.00)$ & \\
\hline Length of hospitalization (mean \pm SD) (days) & $12.02 \pm 7.09$ & $12.2 \pm 7.10$ & 0.97 \\
\hline Number (\%) of pts hospitalized for less than 7 days & $67(61.46)$ & $184(66.90)$ & 0.001 \\
\hline Number (\%) of pts hospitalized for 7-14 days & $16(14.67)$ & $78(28.36)$ & \\
\hline Number (\%) of pts hospitalized for more than 15 days & $26(23.87)$ & $13(4.74)$ & \\
\hline \multicolumn{4}{|l|}{ ICU admission due to exacerbation in the previous year } \\
\hline Mean number of ICU admission \pm SD & $0.14 \pm 0.42$ & $0.22 \pm 0.49$ & 0.08 \\
\hline Number (\%) of pts with no ICU admission & $97(89)$ & $229(83.28)$ & \\
\hline Number (\%) of pts with one admission & $9(8.25)$ & $39(14.18)$ & 0.25 \\
\hline Number (\%) of pts with two to more admissions & $3(2.75)$ & $7(2.54)$ & \\
\hline Mean no of intubation \pm SD & $0.07 \pm 0.32$ & $0.09 \pm 0.30$ & 0.33 \\
\hline Number (\%) of pts with no intubation & I0I (92.68) & $251(91.28)$ & 0.09 \\
\hline Number (\%) of pts with one intubation & $4(3.66)$ & $23(8.36)$ & \\
\hline Number (\%) of pts with two or more intubations & $4(3.66)$ & I $(0.36)$ & \\
\hline
\end{tabular}

Abbreviations: pts, patients; ICU, intensive care unit; SD, standard deviation.

higher in women in USA. ${ }^{12}$ A possible reason for that was the increase in the rate of smoking in women in developed nations. Since then, many anti-tobacco campaigns have been implemented, mostly in developed nations, and rates of smoking started to decrease in successful sites. This trend has a reflector effect on COPD epidemiology in men, but data about the same in women raises the concern that COPD is becoming a women's disease in developed countries. $^{12-16}$

In underdeveloped and developing countries, COPD is still a men's disease and the rate of smoking in women is still less, which is about $10 \%$. However, there have been other noxious sources such as biomass exposure and secondhand smoking that mainly affect women and are

Table 3 Characteristics of the current admission for exacerbation

\begin{tabular}{|c|c|c|c|}
\hline & Females $(n=109)(\%)$ & Males $(n=275)(\%)$ & $\mathbf{P}$ \\
\hline Mean time (days) after symptoms started till the patients were admitted to the ward & $47.82 \pm 15.84$ & $12.34 \pm 10.09$ & 0.001 \\
\hline Hospitalization duration for current exacerbation (mean \pm SD) (days) & $36.80 \pm 4.43$ & $12.32 \pm 6.96$ & 0.001 \\
\hline \multicolumn{4}{|l|}{ Etiologies of exacerbation symptoms, $n$ (\%) } \\
\hline Number (\%) of the pts with tracheobronchial infections (AECOPD) & $4 \mid(37.62)$ & $81(29.45)$ & \\
\hline Number $(\%)$ of the pts with pneumonia & $12(11)$ & $79(28.72)$ & \\
\hline Number (\%) of the pts with pulmonary embolism & $5(4.6)$ & $5(I .8 I)$ & \\
\hline Number (\%) of the pts with congestive heart failure & $10(9.2)$ & $19(6.90)$ & 0.001 \\
\hline Number $(\%)$ of the pts with low treatment adherence & $19(17.39)$ & $35(12.72)$ & \\
\hline Number (\%) of the pts with infected bronchiectasis & $3(2.8)$ & $10(3.63)$ & \\
\hline Number $(\%)$ of the pts with other reasons & $19(17.39)$ & $46(16.77)$ & \\
\hline
\end{tabular}

Abbreviations: pts, patients; AECOPD, acute exacerbation of chronic obstructive lung disease; SD, standard deviation. 
Table 4 Comorbidities of the patients

\begin{tabular}{|c|c|c|c|}
\hline & Females $(n=109)(\%)$ & Males ( $n=275)(\%)$ & $P$ \\
\hline The mean \pm SD of comorbidities & $0.05 \pm 0.21$ & $3.22 \pm 1.99$ & 0.00 \\
\hline The mean Charlson index \pm SD & $0.48 \pm 0.50$ & $3.53 \pm 2.07$ & 0.00 \\
\hline \multicolumn{4}{|l|}{ Charlson index no (\%) } \\
\hline 0 & $56(51.4)$ & $41(15)$ & 0.00 \\
\hline 1 & $53(48.6)$ & $49(17.9)$ & \\
\hline$\geq 2$ & 0 & $185(67.1)$ & \\
\hline Sleep disorders & $13(1 \mid .92)$ & $13(4.72)$ & 0.02 \\
\hline Hypertension & $20(18.34)$ & $145(52.72)$ & 0.00 \\
\hline Arrhythmia & $15(13.76)$ & $67(24.36)$ & 0.03 \\
\hline Coronary artery disease & $34(31.19)$ & 89 (32.36) & 0.82 \\
\hline Diabetes mellitus & $5(4.58)$ & $62(22.54)$ & 0.00 \\
\hline Congestive heart failure & $5(4.58)$ & $70(25.45)$ & 0.00 \\
\hline Hyperlipidemia & $2(1.83)$ & $26(9.45)$ & 0.00 \\
\hline Lung cancer & $24(22.01)$ & $70(25.45)$ & 0.51 \\
\hline Other cancers & $3(2.75)$ & $19(6.90)$ & 0.14 \\
\hline Bronchiectasis & I (0.9I) & $59(21.45)$ & 0.00 \\
\hline Chronic kidney disease & II (I0.09) & $9(3.27)$ & 0.00 \\
\hline Anemia & $26(30.2)$ & $12(4.4)$ & 0.00 \\
\hline Gastroesophageal reflux & $96(87.1)$ & $4 \mid(\mid 4.9)$ & 0.00 \\
\hline
\end{tabular}

Abbreviation: SD, standard deviation.

more prevalent in eastern nations. ${ }^{17}$ Data coming from the People's Republic of China showed that $51.3 \%$ of women and $12.1 \%$ of men were exposed to secondhand smoking at home. ${ }^{18,19}$

In Turkey, the prevalence of smoking was $39.2 \%$ in men and $12.6 \%$ in women in $2012 .{ }^{20}$ Accordingly, the prevalence of COPD in Turkey is approximately $15 \%$ in men and $6 \%$ in women. ${ }^{15}$ It is known that among nonsmokers with COPD, $80 \%$ of them are women. ${ }^{12}$ Among them, the main reason is biomass exposure. In a study performed in Malatya, ${ }^{21}$ biomass was the sole reason for COPD in $54.6 \%$ of women. ${ }^{21}$ Women are obviously more prone to the hazardous effects of indoor air pollution such as cooking smoke and biomass fuel smoke. ${ }^{22}$

Both sexes had a similar current smoking rate, which was approximately $25 \%$, and the passive smoking history was $27 \%$ in women and $7 \%$ in men. Biomass exposure has occurred in both sexes in approximately $47 \%$. Since these are retrospective data from routine hospital records, we did not know the detail of the intensity, the type of the biomass exposure and passive smoking, and other related issues such as socioeconomic status, household income, educational levels, and history of airway hyperresponsiveness.

It is shown that women develop severe COPD at younger ages and with less cumulative cigarette smoke. ${ }^{12,23}$ Hence, they would have higher loss of lung function, higher exacerbation rates, and different types of comorbidities. ${ }^{6,12,24-27}$ There has been some evidence that women may be more susceptible to smoke fume. Women could be genetically and biologically more predisposed to smoking-induced lung damage. Female hormones could have an effect on alveolar structure and adaptive immune response. ${ }^{28}$ Hence, the metabolism of cigarette smoke could be different in the female sex. ${ }^{12,28}$ Women also experience more dyspnea, less phlegm, and poorer quality of life than men..$^{29,30}$

There are only a few number of studies that have been done on COPD exacerbation. In a study conducted in an ER, more men $(n=191)$ reported sputum production, but the proportion

Table 5 Comparison of the drug treatment for COPD

\begin{tabular}{llll}
\hline & Females (n=l 09) (\%) & Males (n=275) (\%) & $\mathbf{P}$ \\
\hline Short-acting $\beta$ 2-adrenergic agonists & $40(36.69)$ & $264(96.0)$ & 0.00 \\
Long-acting $\beta$ 2-adrenergic agonists & $35(32.11)$ & $220(80)$ & 0.00 \\
Short-acting anticholinergic agents & $50(45.87)$ & $58(21.09)$ & 0.00 \\
Long-acting anticholinergic agents & $72(66.05)$ & $230(83.63)$ & 0.01 \\
Inhaler corticosteroids & $40(36.69)$ & $228(82.90)$ & 0.00 \\
Oral corticosteroids & $30(27.52)$ & $3(1.1)$ & 0.00 \\
Theophylline & $3(2.75)$ & $35(12.72)$ & 0.00 \\
\hline
\end{tabular}


of patients with dyspnea was similar in both sexes. Comorbidities were also similarly distributed. In that study, although the women had higher education and similar economical status as men, they were less likely to seek medical attendance within 24 hours prior to ER admission and they were less likely to be self-medicated. ${ }^{31}$ In a study from Singapore, univariate analysis showed that men had a greater risk for readmission due to COPD exacerbations. ${ }^{32}$ There are also different results on mortality due to COPD exacerbations. ${ }^{33-35}$

In our study, in an exacerbation setting, females were admitted to the hospital with a greater $\mathrm{FEV}_{1} / \mathrm{FVC}, \mathrm{FEV}_{1}$, FVC, and $\mathrm{PCO}_{2}$ and lesser $\mathrm{PO}_{2}$ than males. We could not find any previous data on arterial blood gas levels or spirometric parameters taken in exacerbation as comparative measures in sexes in COPD. However, our findings would be interpreted in accordance with Martinez et al. ${ }^{30}$

Although the mean number of exacerbations, the mean number of ICU admissions, and the number of intubations were similar in both sexes in the previous year, more females than men previously exacerbated and hospitalized for two times than men. The prolonged length of hospitalization occurred more in women than males in the previous year. This can be interpreted as women having more severe exacerbations or more instances of hospitalization due to either severity or a different presentation of exacerbation that leads doctors to hospitalize them. Hurst et al showed that the main trigger that predicts the future exacerbation was previous exacerbation history. ${ }^{36}$ Our results led to the question if sex takes any mechanistic role on this issue.

In our study, we also investigated the current admission status. As far as we know, this is the first study that examines the etiology of exacerbation systematically. Tracheobronchial infection occurred in similar frequency, but pulmonary embolism and low treatment adherence were encountered more in women. Although older age is a risk factor for pulmonary embolism, sex is not a known risk factor. We did not evaluate deeply if these emboli patients had additional risk factors such as recent surgery and thrombophilia. However, all five female (4.6\%) patients were over 70 years old and had been administered inhaler steroid. There had been neither hormone therapy nor oral contraceptive. Two of them suffered from cancer with atrial fibrillation. It is suggested that these factors can contribute to pulmonary embolism in females. So we could not explain the relation unless there was a random event. Treatment adherence with inhaler medication has been lower in women than in men in scarce previous studies. ${ }^{12,37}$ We recorded similar results in the current study, and this was one of the reasons for the current instances of exacerbation. Admission data showed an interesting fact that women had a long period of symptoms (approximately 47 days) before hospitalized. They also had a lengthy hospitalization of approximately 40 days. In comparison, both numbers were 12 days in men. These data may show that in Turkey, women could be late in seeking medical attention, they may underestimate their symptoms, or they might have difficulties using health resources. These concepts should be investigated prospectively in a national setting. In previous studies, women and men had the same opportunity using health resources; however, women tended to declare difficulty reaching physicians. ${ }^{33}$

The comorbidity profile has been found to be different in different sexes. Eclipse study showed that while cardiovascular comorbidity and diabetes were less prevalent, osteoporosis, inflammatory bowel disease, reflux disease, and depression are more prevalent in women. ${ }^{26}$ In our study, women had less comorbidity, less hypertension, equal coronary heart disease, less congestive heart failure, less diabetes and similar lung cancer, and more chronic kidney failure, anemia, and gastroesophageal reflux disease. There was not a remarkable depression or psychological disorder encountered.

This study also showed that women were clearly undertreated for COPD. Therefore, they were using more oral corticosteroids. There are data that show that women had a risk of being more underdiagnosed and misdiagnosed when compared to men. ${ }^{6,12,31}$ There may be sex disparity in using health resources. However, studies showed no difference in health coverage and using health resources. We were unable to identify the underlying reasons.

This study had several limitations. This is a single center study. The hospital-based data have been used. The hospital is a tertiary hospital in which may be the severe cases would be admitted more in general. The etiologic relations were not comprehensively examined due to the retrospective design of the study.

In conclusion, current data showed that female COPD patients might be more prone to have severe exacerbations, higher number of hospitalizations, and prolonged length of stay for hospitalization. They have a different comorbidity profile and might be undertreated for COPD. They might also have a long period of symptoms before being admitted to the hospital. The data should be confirmed by the prospective design.

\section{Author contributions}

All authors contributed toward data analysis, drafting and revising the paper and agree to be accountable for all aspects of the work. 


\section{Disclosure}

This research received no specific grant from any funding agency in the public, commercial, or not-for-profit sectors, and all authors report that there are no conflicts of interest.

\section{References}

1. Torres JP, Casanova C, Hernandez C, Abreu J, Aguirre-Jaime A, Celli BR. Gender and COPD in patients attending a pulmonary clinic. Chest. 2005;128:2012-2016.

2. Mannino DM, Homa DM, Akinbami LJ, Ford ES, Redd SC. Chronic pulmonary disease surveillance - United States, 1971-2000. Morb Mortal Wkly Rep. 2002;51(6):1-16.

3. Chapman KR, Tashkin DP, Pye DJ. Gender bias in the diagnosis of COPD. Chest. 2001;119:1691-1695.

4. Tanoue L. Cigarette smoking and women's respiratory health. Clin Chest Med. 2000;1:57-59.

5. Foy CG, Rejeski J, Berry MJ, Zaccaro D, Woodard CM. Gender moderates the effects of exercise therapy on health-related quality of life among COPD patients. Chest. 2001;119:70-76.

6. Celli B, Vestbo J, Jenkins CR, et al; On behalf of the investigators of the TORCH study. Sex differences in mortality and clinical expressions of patients with chronic obstructive pulmonary disease. The TORCH experience. Am J Respir Crit Care Med. 2011;183:317-322.

7. Kocks JW, Vandenberg JW, Kerstjens HA, et al. Day-to-day measurement of patient-reported outcomes in exacerbations of chronic obstructive pulmonary disease. Int J Chron Obstruct Pulmon Dis. 2013;8:273-286.

8. Vestbo J, Hurd SS, Agusti AG, Jones PW, Vogelmeier C, Anzueto A, et al. Global strategy for the diagnosis, management and prevention of chronic obstructive pulmonary disease: GOLD executive summary. Am J Respir Crit Care Med. 2013;187(4):347-365.

9. Celli BR, Macnee W, Agusti A, et al. Standards for the diagnosis and treatment of patients with COPD: a summary of the ATS/ERS position paper. Eur Respir J. 2004;23:932-946.

10. Anthonisen NR, Manfreda J, Warren CP, Hershfield ES, Harding GK, Nelson NA. Antibiotic therapy in exacerbations of chronic obstructive pulmonary disease. Ann Intern Med. 1987;106:196-204.

11. Charlson M, Szatrowski TP, Peterson J, Gold J. Validation of a combined comorbidity index. J Clin Epidemiol. 1994;47:1245-1251.

12. Aryal S, Diaz-Guzman E, Mannino DM. COPD and gender differences: an update. Transl Res. 2013;162(4):208-218.

13. Chen Y, Breithaupt K, Muhajarine N. Occurrence of chronic obstructive pulmonary disease among Canadians and sex-related risk factors. J Clin Epidemiol. 2000;53:755-761.

14. Camp PG, Goring SM. Gender and the diagnosis, management, and surveillance of chronic obstructive pulmonary disease. Proc Am Thorac Soc. 2007;4(8):686-691.

15. Buist AS, Vollmer WM, McBurnie MA. Worldwide burden of COPD in high- and low-income countries. Part I. The burden of obstructive lung disease (BOLD) initiative. Int J Tuberc Lung Dis. 2008;12(7):703-708.

16. Ben-Zaken Cohen S, Pare PD, Man SF, Sin DD. The growing burden of chronic obstructive pulmonary disease and lung cancer in women examining sex differences in cigarette smoke metabolism. Am J Respir Crit Care Med. 2007;176(2):113-120.

17. Becklane MR, Kauffmann F. Gender differences in airway behaviour over the human life span. Thorax. 1999;54(12):1119-1138.

18. Zhou Y, Chen R. Risk factors and intervention for chronic obstructive pulmonary disease in China. Respirology. 2013;18(3):4-9.

19. Gu D, Wu X, Reynolds K, et al; for the InterASIA Collaborative Group. Cigarette smoking and exposure to environmental tobacco smoke in China: the international collaborative study of cardiovascular disease in Asia. Am J Public Health. 2004;94:1972-1976.
20. Kostova D, Andes L, Erguder T, et al; Office on Smoking and Health, National Center for Chronic Disease Prevention and Health Promotion, CDC. Cigarette prices and smoking prevalence after a tobacco tax increase - Turkey, 2008 and 2012. MMWR. 2014;63:457-461.

21. Gunen H, Hacievliyagil SS, Yetkin O, Gulbas G, Mutlu LC, Pehlivan E. Prevalence of COPD: first epidemiological study of a large region in Turkey. Eur J Intern Med. 2008;19(7):499-504.

22. Han MK, Postma D, Mannino DM, et al. Gender and chronic obstructive pulmonary disease why it matters. Am J Respir Crit Care Med. 2007; 176(12):1179-1184.

23. Foreman MG, Zhang L, Murphy J, et al; and the COPD Gene Investigators. Early-onset chronic obstructive pulmonary disease is associated with female sex, maternal factors, and African American race in the COPD Gene Study. Am J Respir Crit Care Med. 2011;184:414-420.

24. Dransfield MT, Davis JJ, Gerald LB, Bailey WC. Racial and gender differences in susceptibility to tobacco smoke among patients with chronic obstructive pulmonary disease. Respir Med. 2006;100:1110-1116.

25. Silverman EK, Weiss ST, Drazen JM, et al. Gender-related differences in severe, early-onset chronic obstructive pulmonary disease. Am J Respir Crit Care. 2000;162:2152-2158.

26. Vestbo J, Anderson W, Coxson HO, et al; Eclipse Investigators. Evaluation of COPD longitudinally to identify predictive surrogate end-points (ECLIPSE). Eur Respir J. 2008;31:869-873.

27. Dales RE, Mehdizadeh A, Aaron SD, Vandemheen KL, Clinch J. Sex differences in the clinical presentation and management of airflow obstruction. Eur Respir J. 2006;28:319-322.

28. Kamil F, Pinzon I, Foreman MG. Sex and race factors in early-onset COPD. Curr Opin Pulm Med. 2013;19:140-144.

29. Katsura H, Yamada K, Wakabayashi R, Kida K. Gender-associated differences in dyspnoea and health-related quality of life in patients with chronic obstructive pulmonary disease. Respirology. 2007; $12: 427-432$

30. Martinez CH, Raparla S, Plauschinat CA, et al. Gender differences in symptoms and care delivery for chronic obstructive pulmonary disease. $J$ Womens Health (Larchmt). 2012;21(12):1267-1274.

31. Cydulka RK, Rowe BH, Clark S, Emerman CL, Rimm AR, Camargo CA. Gender differences in emergency department patients with chronic obstructive pulmonary disease exacerbation. Acad Emerg Med. 2005;12:1173-1179.

32. Cao Z, Ong KC, Eng P, Tan WC, Ng T. Frequent hospital readmissions for acute exacerbation of COPD and their associated factors. Respirology. 2006;11(2):188-195.

33. Raine R, Goldfrad C, Rowan K, Black N. Influence of patient gender on admission to intensive care. J Epidemiol Community Health. 2002;56:418-423.

34. Sunyer J, Antó JM, McFarlane D, et al. Sex differences in mortality of people who visited emergency rooms for asthma and chronic obstructive pulmonary disease. Am J Respir Crit Care Med. 1998;158(3):851-856.

35. Machado MC, Krishnan JA, Buist SA, et al. Sex differences in survival of oxygen-dependent patients with chronic obstructive pulmonary disease. Am J Respir Crit Care Med. 2006;174(5):524-529.

36. Hurst JR, Vestbo J, Anzueto A, et al; for the Evaluation of COPD Longitudinally to Identify Predictive Surrogate Endpoints (ECLIPSE) Investigators. Susceptibility to exacerbation in chronic obstructive pulmonary disease. $N$ Engl J Med. 2010;363:1128-1138.

37. Goodman DE, Israel E, Rosenberg M, Johnston R, Weiss ST, Drazen JM. The influence of age, diagnosis, and gender on proper use of metereddose inhalers. Am J Respir Crit Care Med. 1994;150:1256-1261. 


\section{Publish your work in this journal}

The International Journal of COPD is an international, peer-reviewed journal of therapeutics and pharmacology focusing on concise rapid reporting of clinical studies and reviews in COPD. Special focus is given to the pathophysiological processes underlying the disease, intervention programs, patient focused education, and self management protocols.

This journal is indexed on PubMed Central, MedLine and CAS. The manuscript management system is completely online and includes a very quick and fair peer-review system, which is all easy to use. Visit http://www.dovepress.com/testimonials.php to read real quotes from published authors.

Submit your manuscript here: http://www.dovepress.com/international-journal-of-chronic-obstructive-pulmonary-disease-journal 